\title{
QUALIDADE SANITÁRIA E FISIOLÓGICA, MÉTODOS DE DETECÇÃO DE Fusarium spp. E TRATAMENTO DE SEMENTES DE PUPUNHEIRA
}

\section{SANITARY AND PHYSIOLOGICAL QUALITY, METHODS OF DETECTION AND TREATMENT OF SEEDS OF PEACH PALM}

\author{
José Carlos da Costa Junior ${ }^{1}$ Alvaro Figueredo dos Santos ${ }^{2}$ Luziane Franciscon ${ }^{3}$ \\ Cleiltan Novais da Silva ${ }^{4}$ Dauri José Tessmann ${ }^{5}$
}

\begin{abstract}
RESUMO
Desde o ano 2000 é verificada a ocorrência da doença podridão da base do estipe (PBE), causada por Fusarium spp., em plantios de pupunheira (Bactris gasipaes Kunth. var. gasipaes Henderson). A PBE pode se tornar limitante para o cultivo da pupunheira, ocorrendo em plantas com diferentes idades. Temse verificado a presença do patógeno em sementes. Os objetivos deste trabalho foram: avaliar a qualidade sanitária e fisiológica de oito lotes comerciais de sementes de pupunheira provenientes da região de Porto Velho - RO; avaliar dois métodos de detecção de Fusarium spp. em sementes; avaliar a patogenicidade e agressividade de isolados de Fusarium spp. obtidos de sementes; avaliar o tratamento químico de dois lotes de sementes de pupunheira para o controle de Fusarium spp. Houve grande variação entre os lotes de sementes de pupunheira quanto à germinação, vigor e emergência de plântulas. Fusarium spp. pode ser transmitido das sementes para plântulas causando a doença PBE. A metodologia do papel-cartão para deteç̧ão de Fusarium spp. mostrou-se mais eficaz na recuperação deste patógeno em sementes de pupunheira. Os fungicidas tiofanato metílico+clorotalonil e tiofanato metílico controlaram Fusarium spp. em sementes de pupunheira. Fusarium oxysporum e Fusarium proliferatum, isolados de semente e plântula, respectivamente, foram patogênicos à pupunheira.
\end{abstract}

Palavras-chave: palmito de pupunha; fitopatologia; patologia de sementes.

\section{ABSTRACT}

Basal stem rotting (BSR), caused by Fusarium spp., has been observed in peach palm (Bactris gasipaes Kunth. var. gasipaes Henderson) plantations in Brazil since 2000. The disease is a limiting factor to peach palm farming, damaging plants of different ages. The pathogen presence has been verified in seeds. The objectives of this study were: to evaluate the sanitary and physiological quality of eight commercial lots of peach palm seeds from Porto Velho, state of Rondonia, in Brazil; to compare two detection methods for Fusarium spp. in peach palm seeds; to evaluate pathogenicity and to compare aggressiveness of Fusarium spp. isolates from peach palm seeds; and to evaluate the chemical treatment of two peach palm seed lots for controlling Fusarium spp., about their effects on: a) sanitary effect; b) germination and vigor. The Fusarium spp. pathogenic may be transmitted by seeds to seedlings causing BSR disease. The paperboard methodology for Fusarium spp. detection proved to be more efficient for recovering this pathogen in peach palm seeds. The Chlorothalonil + Thiophanate Methyl and Thiophanate Methyl fungicides achieved the

1 Engenheiro Agrônomo, MSc., Universidade Federal do Paraná, Rua dos Funcionários, 1540, Barirro Juvevê, CEP 80035-050, Curitiba (PR), Brasil. zehagronomo@hotmail.com

2 Engenheiro Agrônomo, Dr., Pesquisador da Embrapa Florestas, Estrada da Ribeira, Km 111, CEP 83411-000, Colombo (PR), Brasil. alvaro.santos@embrapa.br

3 Estatística, MSc., Analista da Embrapa Florestas, Estrada da Ribeira, Km 111, CEP 83411-000, Colombo (PR), Brasil. luziane.franciscon@embrapa.br

4 Engenheira Agrônoma, $\mathrm{Dr}^{\mathrm{a}}$., Pós-doutoranda do Programa de Pós-graduação em Agronomia, Universidade Estadual de Maringá, Av. Colombo, 5790, CEP 87020-900, Maringá (PR), Brasil. cleitan@gmail.com

5 Engenheiro Agrônomo, Dr., Professor do Departamento de Agronomia, Universidade Estadual de Maringá, Av. Colombo, 5790, CEP 87020-900, Maringá (PR), Brasil. djtessmann@uem.br 
effective control over the target pathogen Fusarium spp. in peach palm seeds. Fusarium oxysporum and Fusarium proliferatum isolated from seed and seedling, respectively, were pathogenic to peach palm.

Keywords: peach palm; plant pathology; seed pathology.

\section{INTRODUÇÃO}

A pupunheira (Bactris gasipaes Kunth var. gasipaes Henderson), Arecaceae, vem despertando grande interesse por parte dos agricultores devido as suas múltiplas possibilidades de utilização. No interior da Amazônia, a pupunheira constitui-se em uma valiosa e versátil planta de subsistência. Dela pode-se obter frutos para consumo direto (após cozimento em água e sal), para fabricação de farinha para utilização humana ou animal, óleo, além do palmito, que é de excelente qualidade (CLEMENT; MORA-URPI, 1987). Através do cultivo desta palmeira para produção de palmito, esta espécie poderá exercer um papel preponderante na solução do problema de oferta de matéria-prima no Brasil. $\mathrm{O}$ palmito ou heart of palm, como é conhecido internacionalmente, é um produto de alto valor nos mercados interno e externo, movimentando aproximadamente 350 milhões de dólares por ano, com geração de 8 mil empregos diretos e 25 mil indiretos (BOVI, 2000).

A expansão do cultivo das palmeiras para palmito para diversas regiões brasileiras; a execução de plantios durante todo o ano, às vezes em épocas desfavoráveis; a alta demanda por mudas e o seu manejo inadequado têm favorecido a incidência de problemas bióticos e abióticos, principalmente na fase de produção de mudas (SANTOS et al., 2007). A podridão da base do estipe (PBE), causada por espécies do gênero Fusarium, ocorre em algumas áreas e pode se tornar limitante para o cultivo da pupunheira. A PBE ocorre em plantas de pupunheira com diferentes idades, desde viveiro, sendo mais frequente em plantios com idade entre seis a doze meses (SANTOS et al., 2001).

Nas sementes de pupunheira, segundo Ferreira (1988), verifica-se o ataque de diversos fungos, entre eles várias espécies de Fusarium. Durante a colheita dos frutos de pupunheira, muitas vezes, os mesmos são coletados no chão e, com isso, podem ser contaminados por patógenos de solo. Alguns desses patógenos, como o Fusarium spp., podem associar-se à superfície das sementes e, mais tarde, provocar redução no estande de plantas. Para recuperar esta falha, é necessária uma nova semeadura, o que onera os custos de produção, além do risco da muda infectada levar a doença para o campo (SANTOS et al., 2008). Bovi et al., (1993) afirma que normalmente, os fungos penetram na semente antes da colheita do fruto. Bovi (1998) relata que essa contaminação pode, também, acontecer por ocasião do manuseio e armazenamento inadequados. Dessa forma, podese observar que frente a esta ameaça de entrada de patógenos em novas áreas tendo a sementes como fonte de inóculo, faz-se necessário a inspeção e o tratamento desse material propagativo, a fim de verificar sua qualidade sanitária para evitar a disseminação de patógenos (SANTOS et al., 2011).

Desta forma, o presente trabalho teve como objetivos: a) avaliar a qualidade sanitária e fisiológica de oito lotes comerciais de sementes de pupunheira provenientes da região de Porto Velho - RO; b) avaliar dois métodos de detecção de Fusarium spp. em sementes; c) avaliar a transmissão de Fusarium spp. de sementes para plântulas de pupunheira, assim como a agressividade de isolados obtidos de sementes e inoculados em mudas de pupunheira; d) avaliar o efeito do tratamento químico de dois lotes de sementes de pupunheira para o controle de Fusarium spp., na sanidade e germinação destas.

\section{MATERIAL E MÉTODOS}

\section{Caracterização do local}

O trabalho foi conduzido nos laboratórios de Sementes Florestais e Patologia Florestal e na casa de vegetação da Embrapa Florestas, em Colombo - PR. Para atender aos objetivos propostos, quatro experimentos compostos de oito ensaios foram desenvolvidos no período de dezembro de 2011 a novembro de 2012.

\section{Material vegetal}

Nos experimentos foram avaliados oito lotes comerciais (01A, 02A, 02E, 02G, 02D, VR1, T, RECA) de sementes de pupunheira provenientes da região de Porto Velho - RO. As sementes foram armazenadas adequadamente até a conclusão de todos os ensaios, em local arejado e protegido da luz e do calor, com temperatura em torno de $20^{\circ} \mathrm{C}$. As 
mudas utilizadas foram cedidas pelo viveiro Flora do Vale, localizado em Garuva - SC e encontravamse com 8 meses de idade e 3-4 pares de folhas, em sacos de polietileno preto $(11 \mathrm{~cm}$ de altura e $7 \mathrm{~cm}$ de largura).

\section{Qualidade sanitária de sementes de pupunheira}

\section{Em papel mata-borrão (Blotter test)}

O primeiro método testado foi o Blotter test (NEERGAARD, 1979), sendo utilizadas 100 sementes de cada lote. As sementes foram distribuídas em caixas do tipo gerbox, previamente desinfestadas com algodão embebido em álcool $70 \%$, contendo duas folhas de papel mata-borrão esterilizadas e umedecidas com água destilada esterilizada até atingir elevado grau de umidade, próximo ao seu ponto de saturação, garantindo um ambiente favorável para o crescimento de fungos nas sementes. Cada caixa recebeu dez sementes sobre o papel umedecido, sendo tampadas a seguir (SANTOS et al., 2011). As sementes foram incubadas em sala climatizada sob lâmpadas fluorescentes de $20 \mathrm{~W}$, em fotofase de $12 \mathrm{~h}$, à temperatura de $20 \pm 1^{\circ} \mathrm{C}$, durante sete dias. Em seguida, ocorreu a avaliação e identificação dos fungos.

\section{Em papel-cartão}

As sementes foram dispostas em caixas gerbox também desinfestadas e contendo folhas de papel mata-borrão esterilizado. Sobre estas folhas foi depositada uma folha de papel-cartão azul esterilizado banhado com uma lâmina de meio nutritivo preparado com $15 \mathrm{~g}$ de peptona, $5 \mathrm{~g}$ de $\mathrm{MgSO}_{4} 7 \mathrm{H}_{2} \mathrm{O}, 1 \mathrm{~g}$ de $\mathrm{KH}_{2} \mathrm{PO}_{4}$ e $1 \mathrm{~g}$ de Pentacloronitrobenzeno (PCNB) em $1000 \mathrm{~mL}$ de água destilada (ANDERSON, 1986). As sementes permaneceram incubadas nas mesmas condições que o método anterior, porém, por um maior período de tempo (14 dias). Ao término do período de incubação em ambos os métodos, as sementes foram retiradas e levadas ao laboratório para avaliação por meio da inspeção do material com auxílio de microscópio estereoscópico para realizar a identificação e a quantificação dos fungos. Quando necessário, foram confeccionadas lâminas para visualização, em microscópio óptico, das estruturas do fungo-alvo e a determinação do gênero, conforme descrições de Barnett e Hunter (1972).

\section{Transmissão}

Para o teste de transmissão de patógenos das sementes às plântulas, foram testados oito tratamentos, considerando que cada um foi composto por 100 sementes de cada um dos oito lotes, em duas repetições de 50 sementes cada. As sementes foram colocadas em caixas plásticas, com o fundo vazado para escoamento do excesso de água, nas dimensões de $50 \times 30 \mathrm{~cm}$, preenchidas com vermiculita autoclavada. O material foi mantido em casa de vegetação. A cada sete dias após a semeadura foram feitas avaliações observando a ocorrência de sintomas em plântulas.

Ao término do teste, as sementes não germinadas foram lavadas com água corrente e, a seguir, submetidas ao teste de sanidade com papelcartão, conforme Anderson (1986). As plântulas sintomáticas foram retiradas do substrato e lavadas com água corrente e, a seguir, colocadas em câmara úmida por sete dias, a temperatura de $20 \pm 1^{\circ} \mathrm{C}$. Após este período, as plântulas com sintomas foram analisadas para verificar a presença de sinais do patógeno, com o auxílio de microscópio estereoscópio e óptico.

Calculou-se a taxa de transmissão do patógeno, da semente para as plântulas, a partir da fórmula sugerida por Forcelini (1991): T.T $(\%)=$ (T.I (\%) x 100) /I.S (\%); em que: T.I = taxa de infecção em plântulas de pupunheira com sintomas de PBE; I.S = incidência de Fusarium spp. em sementes (teste de sanidade com papel-cartão).

\section{Qualidade fisiológica das sementes de pupunheira}

\section{Teor de água}

Para determinação do teor de água das sementes foi conduzido o método da estufa a $105^{\circ} \pm$ $3^{\circ} \mathrm{C}$ por $24 \mathrm{~h}$ (BRASIL, 2009). Para isso, utilizouse uma balança de precisão de $0,001 \mathrm{~g}$, cadinhos numerados e tarados, nos quais foram depositadas cinco sementes em cada. Os oito tratamentos foram constituídos pelos lotes de sementes, com duas repetições de cinco sementes cada.

\section{Germinação}

Para o teste de germinação foram utilizadas 100 sementes de cada um dos lotes comerciais (01A, 02A, 02E, 02G, 02D, VR1, T, RECA), que constituíram os oito tratamentos dos lotes, divididas 
em quatro repetições de 25 sementes, dispostas em delineamento inteiramente casualizado. As sementes foram dispostas em caixas de plástico com dimensões de $20 \times 30 \mathrm{~cm}$, previamente desinfestadas com álcool $70 \%(\mathrm{v} / \mathrm{v})$, conforme metodologia padrão do laboratório de Sementes Florestais da Embrapa Florestas. As caixas foram preenchidas com aproximadamente $3,5 \mathrm{~kg}$ de areia grossa, segundo classificação na escala granulométrica de Atterberg $(0,2-2,0 \mathrm{~mm})$, peneirada em malha 2 $\mathrm{mm}$, lavada e autoclavada.

As sementes foram incubadas em germinador à temperatura de $30^{\circ} \mathrm{C}$. Regas semanais com água destilada foram realizadas, a fim de manter o substrato com umidade suficiente e aeração satisfatória.

A contagem de sementes germinadas foi realizada três vezes por semana, durante 80 dias, removendo-se cuidadosamente a areia superficial para facilitar visualização das estruturas da semente germinada. O primeiro sinal visível da germinação corresponde ao eriçamento das fibras do tampão fibroso, uma porção que emerge da semente e surge como uma massa de células não diferenciadas, chamada de botão germinativo. Posteriormente, o botão germinativo torna-se cilíndrico, diferenciandose em primórdios caulinares e radiculares formando a lígula e a plúmula, uma estrutura tubular que se destaca com o desenvolvimento das estruturas seguintes (FERREIRA, 2005). A semente foi considerada germinada a partir da visualização da massa cotiledonar esbranquiçada na região do opérculo, com formação do botão germinativo.

\section{Emergência}

Para a determinação de plântulas emergidas, oito lotes comerciais de sementes de pupunheira foram mantidos em casa de vegetação dispostos em canteiro de $7,20 \times 0,60 \mathrm{~m}$ de área útil, com oito parcelas de $0,54 \mathrm{~m}^{2}$. O substrato consistiu de areia grossa $(0,2-2,0 \mathrm{~mm})$ lavada, não peneirada, permanecendo com agregados graúdos $(>2,0$ $\mathrm{mm}$ ) como britas e cascalhos. A irrigação da casa de vegetação foi automatizada, com sistema de irrigação por microaspersão com quatro regas diárias de 15 minutos de duração cada, convencionadas nos horários $8 \mathrm{~h} ; 11 \mathrm{~h} ; 14 \mathrm{~h}$ e $17 \mathrm{~h}$.

O critério utilizado na avaliação da emergência foi a visualização e contagem de estruturas visíveis das plântulas acima do nível do substrato. Na parte inferior da lígula emerge uma raiz e na porção superior surge a primeira bainha plumular. A segunda bainha plumular surge de dentro da primeira e, dessa, emerge o primeiro eófilo com folha bífida (FERREIRA, 2005).

A contagem de plântulas emergidas foi realizada semanalmente, durante 120 dias. Ao término deste período, foi realizada a última contagem de plântulas emergidas e retiradas às sementes não germinadas, sendo classificadas como sementes duras (aparentemente dormentes) e mortas (em estágio de decomposição).

As sementes duras, não germinadas, foram lavadas e colocadas em câmara úmida à temperatura ambiente de laboratório durante 10 dias. Durante esse período foi observado se houve algum crescimento fúngico nas mesmas.

\section{Vigor}

Foram avaliados a porcentagem de sementes germinadas e plântulas emergidas, a velocidade e o índice de germinação e emergência. Foram feitas observações diárias até o aparecimento da primeira semente germinada, ou plântula emergida, conforme o experimento. Contou-se, a cada dois dias, o número de sementes germinadas/ plântulas emergidas de cada linha ou repetição, sendo estabelecido conforme metodologia padrão do laboratório de Sementes Florestais da Embrapa Florestas, durante 80 dias para germinação e 120 dias para emergência.

Para o cálculo de velocidade de germinação/ emergência, emprega-se a fórmula de Edmond e Drapala (1958): VE ou VG $=\left\{\left(\mathrm{N}_{1} \times \mathrm{E}_{1}\right)+\left(\mathrm{N}_{2}+\mathrm{E}_{2}\right)+\right.$ $\left.\ldots+\left(\mathrm{N}_{\mathrm{n}}+\mathrm{E}_{\mathrm{n}}\right)\right\} / \mathrm{E}_{1}+\mathrm{E}_{2}+\ldots+\mathrm{E}_{\mathrm{n} .}$

Em que: $V E=$ Velocidade de emergência ou VG para germinação em sementes. $E_{1}, E_{2}, E_{n}$ = número de plântulas emergidas, computadas na primeira, segunda, ..., ultima contagem; $\mathrm{N}_{1}, \mathrm{~N}_{2}, \ldots$ $\mathrm{N}_{\mathrm{n}}=$ número de dias da semeadura à primeira, segunda, ..., última contagem.

Outro parâmetro analisado foi o índice de velocidade emergência/germinação, obtido pelo somatório da razão do número de plântulas emergidas/sementes germinadas, computadas nas avaliações, pelo número de dias da semeadura da primeira a última contagem. Utilizando-se da fórmula de Edmond e Drapala (1958), para IVE ou $I V G=\left(E_{1} / N_{1}+E_{2} / N_{2}+\ldots+E n / N_{n}\right)$.

Foi determinado também o vigor relativo do lote, em função do percentual de plântulas normais vigorosas, obtida pelos testes de germinação e 
emergência. O estádio com o "primeiro eófilo expandido" também conhecido como "primeira folha bífida expandida" foi considerado como critério para caracterização da formação de uma "plântula normal" (FERREIRA, 2005).

Foram consideradas sementes duras aquelas que permaneceram sem absorver água por um período de tempo mais longo que o normal e no final dos testes, estavam com aspecto de sementes recémcolocadas no substrato, isto é, não intumescidas. Foram consideradas como sementes mortas, aquelas que no final do teste não germinaram, apresentandose amolecidas, atacadas por microrganismos e não apresentavam nenhum sinal de germinação (BRASIL, 2009).

\section{Agressividade de isolados de Fusarium sp. obtidos de sementes de pupunheira}

Isolados de Fusarium spp. foram obtidos a partir de sementes contaminadas nos testes de avaliação da qualidade sanitária. Os isolamentos foram feitos em meio batata-ágar-dextrose (BDA) suplementado com ampicilina (80 ppm) e cloranfenicol (40 ppm) e, então, incubados em BOD por dez dias a $24^{\circ} \mathrm{C}$, até o aparecimento de colônias de Fusarium spp.

A identificação das espécies foi realizada com o uso da reação da polimerase em cadeia (PCR). Isolados monospóricos foram cultivados em meio batata-dextrose (BD), a $24{ }^{\circ} \mathrm{C}\left( \pm 2^{\circ} \mathrm{C}\right)$ com fotoperíodo de $12 \mathrm{~h}$ por 4 dias e da massa micelial foi extraído DNA genômico pelo método CTAB descrito por Doyle e Doyle (1991). O DNA foi utilizado na PCR para a amplificação de um segmento do gene fator de elongação - 1 alfa, à porção de aproximadamente $580 \mathrm{pb}$, com os primers Ef1 e Ef2 e o protocolo descrito por Geiser et al. (2004). Os fragmentos de DNA foram purificados com o kit ExoSap-IT (GE Health Care, Little Chalfont, Reino Unido), segundo o protocolo estabelecido pelo fabricante, e encaminhados para sequenciamento no Centro de Estudos do Genoma Humano da Universidade de São Paulo. Para a identificação da espécie, as sequências de DNA obtidas, foram comparadas com sequências disponíveis no banco de dados Fusarium-IDv.1.0 (http://fusarium.cbio. psu.edu) (GEISER et al., 2004).

Os isolados foram inoculados por meio da metodologia de injeção de suspensão de conídios de Fusarium spp. em mudas com oito meses de idade. $\mathrm{O}$ método consistiu em fazer uma incisão na base do colo da muda, previamente desinfestado com álcool $70 \%$ (v/v), utilizando uma seringa descartável com agulha hipodérmica nas dimensões de 1,20 x 40 $\mathrm{mm}$. Neste ponto, procedeu-se a injeção de uma alíquota de $0,1 \mathrm{~mL}$ de suspensão de conídios a uma concentração de $3,25 \times 10^{6}$ conídios $/ \mathrm{mL}$, injetandose água destilada e esterilizada no tratamento testemunha.

A avaliação foi realizada semanalmente, verificando-se a presença de plantas sintomáticas. Para a avaliação foi usada uma escala descritiva, com notas de 1 a 4 (COSTA JÚNIOR, 2013).

\section{Tratamento químico de sementes de pupunheira para o controle de Fusarium spp}

Dois lotes de sementes de pupunheira (02E e VR1) foram previamente selecionados com base no ensaio anterior de sanidade Blotter test, apresentando os seguintes valores de incidência de Fusarium sp.: lote 02E - 4\% e lote VR1 - 7\%.

As sementes de ambos os lotes receberam tratamento químico com três fungicidas e hipoclorito de sódio a 3\%. O experimento constitui-se em seis tratamentos nas respectivas doses de ingrediente ativo (i.a.) em g/ $1 \mathrm{~kg}$ de sementes dos seguintes produtos: captana - 1,25 g i.a/ $1 \mathrm{~kg}$ de sementes; clorotalonil + tiofanato metílico $-0,3+0,75 \mathrm{~g}$ i.a/ $\mathrm{kg}$ de sementes; tiofanato metílico - $0,7 \mathrm{~g}$ i.a/ $1 \mathrm{~kg}$ de sementes; captana + tiofanato metílico - 1,25 $+0,7 \mathrm{~g}$ i.a/ $1 \mathrm{~kg}$ de sementes; hipoclorito de sódio (NaOCL) a 3\% e testemunha. Os tratamentos foram dispostos em delineamento inteiramente casualizado seguindo o esquema fatorial $6 \times 2$ (produtos $\mathrm{x}$ lotes de sementes).

No preparo do tratamento com fungicida foi adicionada água, correspondente a $5 \%$ do peso médio das sementes. As sementes foram colocadas em um saco plástico e agitadas com a solução fungicida durante cinco minutos. Para o tratamento de $\mathrm{NaOCI}$ a $3 \%$, as sementes ficaram imersas na solução durante 10 minutos.

\section{Teste de sanidade}

Após as sementes receberem os respectivos tratamentos, procedeu-se o teste de sanidade, Blotter test (NEEGARD, 1979), conforme procedimentos adotados no teste de sanidade anterior. Os tratamentos foram constituídos de dois lotes comerciais de sementes de pupunheira (02E e VR1), submetidas a seis tratamentos, seguindo o 
esquema fatorial $2 \times 6$ (lotes x métodos), dispostos no delineamento inteiramente casualizado com cinco repetições de 20 sementes cada. Os resultados dos tratamentos foram expressos em porcentagem de cada fungo detectado por lote.

\section{Germinação e vigor}

Após o tratamento das sementes foi realizado o teste de germinação e vigor, conforme metodologia descrita anteriormente. Houve apenas uma pequena modificação em relação ao recipiente, utilizandose caixa tipo gerbox $(11 \mathrm{X} 11 \mathrm{~cm})$. Colocou-se 20 sementes em cada gerbox, constituindo-se cinco repetições por lote. Os demais fatores como temperatura, substrato e umidade, foram mantidos conforme experimento de germinação anterior.

\section{RESULTADOS E DISCUSSÃO}

\section{Qualidade sanitária de sementes de pupunheira}

O teste de médias não foi significativo na comparação entre as metodologias testadas para detecção de Fusarium spp. (Figura 1). No entanto, verificou-se a redução da presença de outros fungos no papel-cartão, facilitando a visualização do patógeno-alvo, Fusarium spp. (Figura 1). O método do papel-cartão para detecção de Fusarium spp. em sementes de pupunheira mostrou-se mais eficiente, atingindo incidências médias superiores ao método Blotter test (Figura 1). Mesmo as sementes sendo incubadas por 14 dias no papel-cartão, o dobro do tempo para o Blotter test, houve redução da presença de fungos contaminantes, desta maneira apresentando índice de contaminação inferior ao Blotter test. Esta observação também já foi feita por vários autores (NEERGAARD, 1973; REIS et al., 1999).

No Blotter test verificou-se alta incidência de fungos contaminantes (Figura 2). Neste método, as colônias de Fusarium spp. apresentaram pouco crescimento, quando comparadas a outros fungos. Os fungos

contaminantes detectados foram: Aspergillus sp ., Trichoderma sp., Penicillium sp., Botrytis sp., Nigrospora sp. e Trichothecium sp. Alguns destes fungos, Aspergillus sp ., Trichoderma sp., Penicillium sp., causam danos às sementes no período de armazenamento em condições inadequadas (SANTOS et al., 2011).

Em estudos com fungos associados a sementes de nove lotes comerciais de pupunheira dos anos de 2008, 2009 e 2010, Santos et al. (2011) relataram a presença de vários fitopatógenos, destacando-se o gênero Fusarium com valores

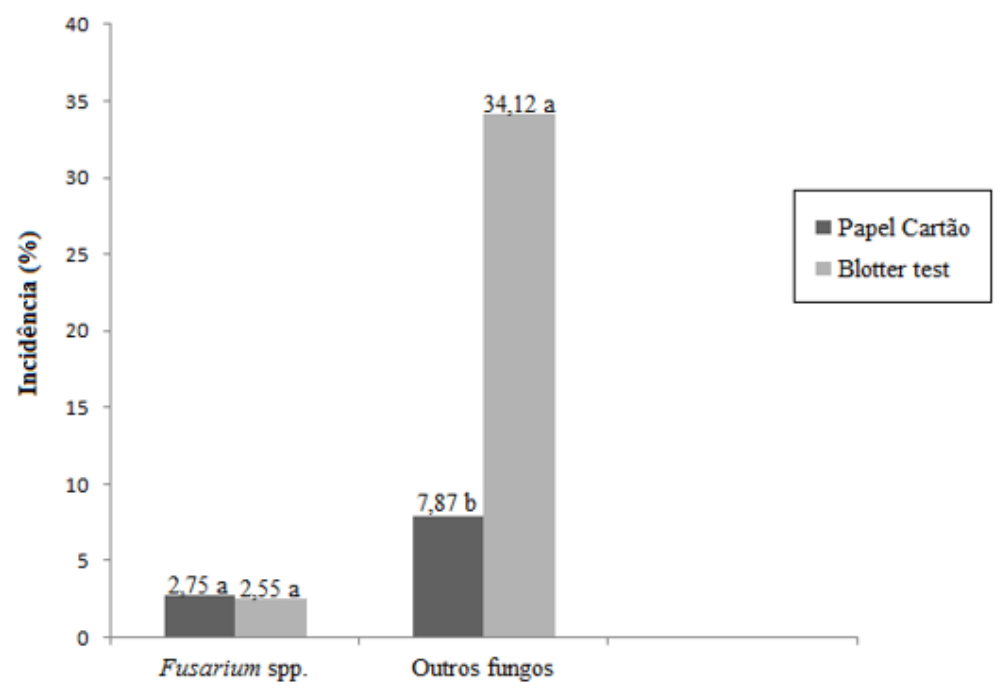

FIGURA 1: Incidência (\%) de Fusarium spp. e outros fungos em oito lotes comerciais de sementes de pupunheira oriundas da região de Porto Velho - RO. Médias seguidas pela mesma letra na coluna não diferem estatisticamente entre si, pelo teste de Tukey, a 5\% de probabilidade de erro.

FIGURE 1: Fusarium spp. and other fungi incidence (\%) in eight commercial lots of peach palm seed from the region of Porto Velho - RO state. Averages followed by the same letter in the column do not differ statistically among themselves by Tukey test at $5 \%$. 


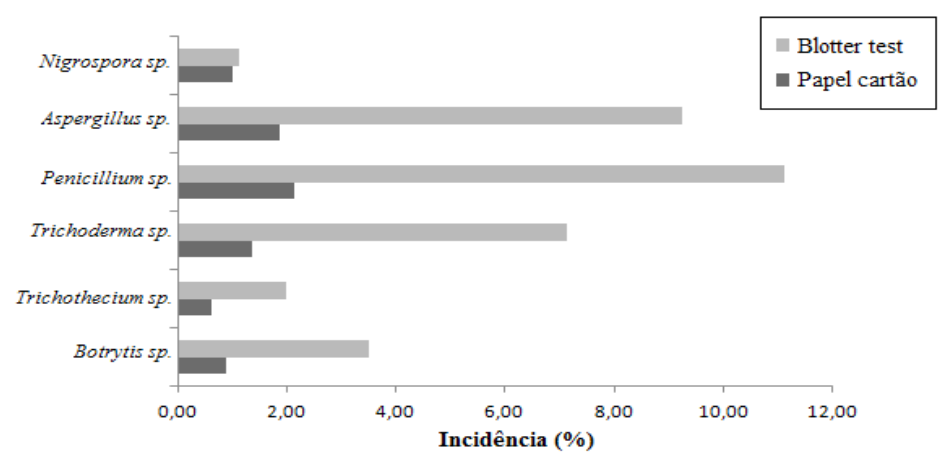

FIGURA 2: Incidência (\%) de outros fungos detectados em oito lotes comerciais de sementes de pupunheira oriundas da região de Porto Velho - RO.

FIGURE 2: Incidence (\%) of the other fungi detected in eight other commercial batches of peach palm seed from the region of Porto Velho - RO state.

atingindo $45,7 \%$ de sementes contaminadas. Enquanto que Bovi et al. (1993) detectaram a presença Fusairum oxysporum, assim como outros fungos, em sementes de pupunheira importadas do Peru. Estes autores consideraram que a presença destes microrganismos em sementes de pupunheira estava também associada a lotes com baixa porcentagem de germinação. Por ser um dos agentes causais da PBE, e um fungo habitante do solo de difícil controle, Santos, Parisi e Menten (2011) enfatizam a adoção de medidas de controle que minimizem os riscos de introdução em novas áreas via sementes ou mudas contaminadas.

\section{Transmissão}

Os resultados do teste de transmissão de Fusarium spp. demonstram que sementes contaminadas podem transmitir Fusarium spp. para plântulas (Tabela 1).

Os lotes que apresentaram os maiores valores de transmissão foram VR1, 02E e T. Este método permitiu a expressão do potencial do inóculo dos patógenos associados a sementes (LUCCA FILHO, 1991), enquanto que a taxa de transmissão (Tabela 1) mostrou que a transmissão de Fusarium spp. pode ser considerada alta, evidenciado pelas taxas com valores iguais ou superiores a $50 \%$.

As sementes não germinadas coletadas do substrato e submetidas à câmara úmida, ao término do ensaio, apresentaram-se contaminadas por Fusarium spp. (Tabela 1), mostrando a ação do patógeno na fase de germinação das sementes.
No Brasil, há poucas informações sobre os microrganismos que ocorrem nas sementes de pupunheira (BOVI et al., 1993; SANTOS et al., 2011) e sua transmissão para as plântulas. Santos, Parisi e Menten (2011) verificaram a transmissão de Fusarium sp. (0,5\%) das sementes para as plântulas.

\section{Qualidade Fisiológica de sementes de pupunheira}

\section{Teor de água}

O teor de água apresentou variações significativas nos lotes de sementes de pupunheira (Tabela 2). Estas variações também foram observadas por Bovi (2000), em lotes que apresentaram diferenças significativas de teor de água inicial, germinação e vigor. Sobre as causas destas variações, Bovi (2000) associaram com a colheita e manuseio das sementes, pelas condições agrobioclimáticas de cultivo e, possivelmente, componente genético.

Ferreira e Santos (1992) afirmaram que a pupunheira é uma espécie recalcitrante, sendo que, o teor de água das mesmas não pode ser reduzido abaixo de um determinado grau de umidade, sem que ocorram danos fisiológicos. Estes autores demonstraram que, embora a redução da umidade de $45 \%$ para $38 \%$ não tenha influenciado de maneira significativa a emergência, ao alcançar $30 \%$ houve queda acentuada da viabilidade das sementes resultando em redução da taxa de emergência das mesmas. Bovi (2000) verificaram também que sementes de pupunheira são sensíveis 
TABELA 1: Emergência de plântulas, taxa de transmissão de Fusarium spp. e incidência do patógeno em plântulas e sementes não germinadas em oito lotes comerciais de sementes de pupunheira oriundos da região de Porto Velho - RO.

TABLE 1: Seedling emergence, transmission rate of the pathogen and incidence of Fusarium spp. in eight commercial lots of peach palm seed from the region of Porto Velho - RO state.

\begin{tabular}{ccccc}
\hline & & & \multicolumn{2}{c}{ Detecção de Fusarium spp. (\%) } \\
\hline LOTES & Emergência (\%) & Taxa de transmissão (\%) & $\begin{array}{c}\text { Plântulas } \\
\text { emergidas }\end{array}$ & $\begin{array}{c}\text { Sementes não } \\
\text { germinadas }\end{array}$ \\
\hline 1A & $13 \mathrm{~b}$ & 50 & 1 & 2 \\
$2 \mathrm{~A}$ & $9 \mathrm{~b}$ & 67 & 0 & 1 \\
O2E & $11 \mathrm{~b}$ & 100 & 4 & 8 \\
O2G & $14 \mathrm{~b}$ & 50 & 1 & 2 \\
O2D & $20 \mathrm{ab}$ & 0 & 0 & 2 \\
RECA & $29 \mathrm{ab}$ & 0 & 0 & 5 \\
T & $35 \mathrm{a}$ & 100 & 3 & 9 \\
VR1 & $33 \mathrm{a}$ & 86 & 6 & 5 \\
\hline
\end{tabular}

Em que: Médias seguidas pela mesma letra na coluna, não diferem entre si, pelo teste de Tukey, a $5 \%$ de probabilidade de erro.

TABELA 2: Médias dos teores de água em oito lotes comerciais de sementes de pupunheira oriundos da região de Porto Velho - RO.

TABLE 2: Averages of water content in eight commercial lots of peach palm seed from the region of Porto Velho - RO state.

\begin{tabular}{cc}
\hline Lotes & Teor de água (\%) \\
\hline VR1 $16,49 \mathrm{a}$ \\
$\mathrm{T}$ & $43,96 \mathrm{ab}$ \\
RECA & $41,41 \mathrm{ab}$ \\
$02 \mathrm{G}$ & $38,87 \mathrm{ab}$ \\
$01 \mathrm{~A}$ & $35,36 \mathrm{ab}$ \\
$02 \mathrm{E}$ & $35,03 \mathrm{ab}$ \\
$02 \mathrm{~A}$ & $34,31 \mathrm{~b}$ \\
02D & $34,07 \mathrm{~b}$
\end{tabular}

Em que: Médias seguidas pela mesma letra na coluna, não diferem entre si, pelo teste de Tukey a $5 \%$ de probabilidade de erro.

à desidratação, com germinação inicial alta quando não desidratadas (47 a $38 \%$ de umidade inicial). Teores de água abaixo da faixa de 28 a $23 \%$ reduziram significativamente a germinação e 0 vigor (BOVI, 2000).

\section{Germinação}

Os oito lotes apresentaram diferenças significativas de germinação (Tabela 3). Os dados de germinação de sementes apresentaram os maiores valores para os lotes T, RECA, VR1 e 02D, com $75,74,66$ e 53\%, respectivamente. Os maiores valores de germinação de sementes encontrados neste trabalho - 53 a $75 \%$-, concordam com resultados obtidos por Bovi (2000). Estes autores apontam as seguintes características para sementes de pupunheira: germinação inicial alta (59 a 84\%), quando não sujeitas à desidratação (47 a $38 \%$ de umidade inicial). 
TABELA 3: Porcentagem média de sementes germinadas, plântulas normais e anormais, sementes duras e mortas em oito lotes comerciais de sementes de pupunheira oriundos da região de Porto Velho - RO.

TABLE 3: Average percentage of germinated seeds, normal and abnormal seedlings, hard seeds and dead in eight other commercial from the region of Porto Velho - RO.

\begin{tabular}{cccccc}
\hline Lotes & Germinação & Plântulas normais & Plântulas anormais & Sementes duras & Sementes mortas \\
\hline T & $75 \mathrm{a}$ & $75 \mathrm{a}$ & 0 & $22 \mathrm{~b}$ & $3 \mathrm{abc}$ \\
RECA & $74 \mathrm{a}$ & $74 \mathrm{a}$ & 0 & $26 \mathrm{~b}$ & $0 \mathrm{abc}$ \\
VR1 & $66 \mathrm{ab}$ & $66 \mathrm{ab}$ & 0 & $26 \mathrm{~b}$ & $8 \mathrm{abc}$ \\
$02 \mathrm{D}$ & $53 \mathrm{abc}$ & $53 \mathrm{abc}$ & 0 & $40 \mathrm{~b}$ & $7 \mathrm{abc}$ \\
$02 \mathrm{G}$ & $48 \mathrm{bc}$ & $48 \mathrm{bc}$ & 0 & $47 \mathrm{a}$ & $5 \mathrm{abc}$ \\
$02 \mathrm{~A}$ & $46 \mathrm{bc}$ & $46 \mathrm{bc}$ & 0 & $41 \mathrm{a}$ & $13 \mathrm{abc}$ \\
$02 \mathrm{E}$ & $43 \mathrm{c}$ & $43 \mathrm{c}$ & 0 & $46 \mathrm{a}$ & $11 \mathrm{abc}$ \\
$01 \mathrm{~A}$ & $41 \mathrm{c}$ & $41 \mathrm{c}$ & 0 & $50 \mathrm{a}$ & $9 \mathrm{abc}$ \\
\hline
\end{tabular}

Em que: Médias seguidas pela mesma letra na coluna, não diferem entre si, pelo teste de Tukey, a $5 \%$ de probabilidade de erro.

A perda de viabilidade está associada com a diminuição de umidade das sementes de pupunheira (FERREIRA; SANTOS, 1992; BOVI, 2000; CARVALHO; MÜLLER, 1998), obrigando à semeadura imediata, o que nem sempre é possível, devido às distâncias entre os locais de obtenção das sementes e os do plantio (SANTOS et al., 2008). Dessa forma, as sementes devem ser semeadas preferencialmente logo após o beneficiamento, pois perdem rapidamente a viabilidade com a redução do grau de umidade.

\section{Vigor}

Os lotes T e Reca apresentaram os menores valores para velocidade de germinação (VG) e velocidade de emergência (VE) e maiores valores para índice de velocidade de germinação (IVG) e índice de velocidade de emergência (IVE) (Tabela 4).

Consideram-se como melhores VG e VE as menores médias obtidas por lote de semente, pois estas indicam que o mesmo levou menos dias para completar a germinação e a emergência. Quanto maiores forem o IVG e o IVE, subentendese melhores VG e VE e, consequentemente, maior vigor do lote, cujo índice calculado estima o número médio de plântulas normais por dia. Com estes resultados pode-se inferir que os lotes $\mathrm{T}$, Reca e VR1 são os mais vigorosos.

$\mathrm{O}$ teste de vigor foi baseado em dados dos ensaios anteriores de germinação e emergência.
Foram avaliados a porcentagem de plântulas germinadas e emergidas, a velocidade e o índice de germinação e emergência, por serem associados, frequentemente, de forma positiva, com o vigor de plantas de pupunheira, tanto em condições de viveiro como de campo (BOVI et al., 1993; BOVI, 1998). Vale lembrar que entre as duas fórmulas (IVE e VE), alguns autores (NAKAGAWA et al., 1983; CROCOMO et al., 1989; TSUBOI, 1990) têm mostrado maior sensibilidade para IVE.

\section{Emergência}

Os lotes RECA e $\mathrm{T}$ destacaram-se em relação aos demais, apresentando um maior número de sementes germinadas. De acordo com Moro (1999), sementes que germinam primeiro produzem mudas mais vigorosas que, quando transplantadas para o campo, continuam destacando-se pelo vigor e precocidade. Enquanto que, mudas de sementes que germinam tardiamente (após 120 dias) têm um crescimento bem mais lento no campo.

Os maiores percentuais de plântulas emergidas foram obtidos nos seguintes lotes: $\mathrm{T}$ - 48\%; RECA - 42\%; VR1 - 40\% e 02D - 31\%. Enquanto que, os lotes com menores emergências foram: $02 \mathrm{G}-25 \%$; $02 \mathrm{~A}-22 \%$; $02 \mathrm{E}-20 \%$ e $01 \mathrm{~A}$ $-16 \%$.

As sementes não germinadas, coletadas e examinadas após o término do teste de emergência, apresentavam diferentes estádios de desenvolvimento, indicando grande 
TABELA 4: Médias dos valores de índice de velocidade de germinação (IVG), velocidade de germinação (VG), índice de velocidade de emergência (IVE) e velocidade de emergência (VE) obtidos nos testes de germinação e emergência em oito lotes comerciais de sementes de pupunheira oriundos da região de Porto Velho - RO.

TABLE 4: Average values of germination speed index, germination speed, emergence speed index and emergence speed obtained in germination and emergence in eight other commercial from the region of Porto Velho - RO state.

\begin{tabular}{cccccc}
\hline Lotes & IVG & VG & IVE & \multicolumn{2}{c}{ VE } \\
\hline T & $0,68 \mathrm{a}$ & $34,8 \mathrm{~d}$ & $0,065 \mathrm{a}$ & 69 & $\mathrm{~d}$ \\
RECA & $0,48 \mathrm{~b}$ & $47,4 \mathrm{c}$ & $0,056 \mathrm{ab}$ & $85 \mathrm{bc}$ \\
VR1 & $0,37 \mathrm{bc}$ & $56,3 \mathrm{abc}$ & $0,042 \mathrm{bc}$ & $88 \mathrm{bc}$ \\
$02 \mathrm{D}$ & $0,28 \mathrm{~cd}$ & $58,8 \mathrm{ab}$ & $0,028 \mathrm{cde}$ & $84 \mathrm{bc}$ \\
$02 \mathrm{G}$ & $0,28 \mathrm{~cd}$ & $51,8 \mathrm{bc}$ & $0,034 \mathrm{~cd}$ & $84 \mathrm{bc}$ \\
$02 \mathrm{~A}$ & $0,25 \mathrm{~cd}$ & $58,2 \mathrm{ab}$ & 0,014 & $\mathrm{e}$ & $100 \mathrm{a}$ \\
$02 \mathrm{E}$ & $0,23 \mathrm{~cd}$ & $63,3 \mathrm{a}$ & $0,021 \mathrm{de}$ & $100 \mathrm{a}$ \\
$01 \mathrm{~A}$ & $0,20 \mathrm{~d}$ & $61,5 \mathrm{ab}$ & $0,022 \mathrm{de}$ & $96 \mathrm{ab}$ \\
\hline
\end{tabular}

Em que: Médias seguidas pela mesma letra na coluna, não diferem entre si, pelo teste de Tukey a $5 \%$ de probabilidade de erro.

desuniformidade na germinação e emergência das mesmas. Observou-se que, ocorreram grandes variações quanto ao número de sementes germinadas, emergidas, plântulas normais, anormais, sementes mortas e duras. Os dados obtidos neste trabalho corroboram as informações de Meerow (1991), de que as sementes de palmeiras são consideradas de germinação lenta e desigual.

Em estudos com sementes de pupunheira, Ferreira e Santos (1992) relatam que a emergência das plântulas teve início entre 50 e 60 dias após a semeadura, tendo alcançado sua estabilização entre 120 e 130 dias. Esses resultados concordam com os de Cardoso (1944) que observou um período de 100 a 150 dias. No presente trabalho, a emergência média ocorreu aos 69 dias, estabilizando aos 120 dias após a semeadura.

Nas sementes não germinadas, submetidas à câmara úmida, foram detectados os seguintes fungos: Fusarium spp., Trichoderma sp.; Trichothecium sp.; Alternaria sp.; Bipolaris sp.; Rhyzopus sp.; Penicillium sp.; Aspergillus sp.

\section{Agressividade de isolados de Fusarium sp. obtidos de sementes de pupunheira}

Aos 42 dias após a inoculação (DAI), o isolado SP5 já apresentava $100 \%$ de plantas sintomáticas, eaos 72 dias todas as plantas inoculadas já estavam mortas (Tabela 5). O isolado SP5 de Fusarium sp. foi considerado o mais agressivo (Tabela 5). Enquanto que o isolado 3A apresentou, aos 63 DAI, sintomas em todas as plantas, porém, com menor severidade. $\mathrm{O}$ isolado $1 \mathrm{~A}$, apresentou uma incidência de $80 \%$ de plantas sintomáticas aos 63 DAI, e apenas três plantas mortas ao final do experimento.

A identificação molecular dos isolados SP5 e $1 \mathrm{~A}$ revelou que os mesmos pertencem às espécies Fusarium proliferatum e Fusarium oxysporum, respectivamente, ambos com identidade superior a 98\%. Os três isolados de Fusarium spp. foram patogênicos à pupunheira. Das duas espécies de Fusarium - Fusarium proliferatum e Fusarium oxysporum - encontradas no presente trabalho, apenas Fusarium oxysporum já foi relatada em pupunheira por Pizzinatto et al. (2001). Há relatos da associação de outras espécies, tais como: Fusarium subglutinans, Fusarium moniliforme, Fusarium solani e Fusarium antrhophilum (PIZZINATTO et al., 2001).

\section{Tratamento químico de sementes de pupunheira para o controle de Fusarium spp.}

$$
\text { Apenas os tratamentos tiofanato }
$$


TABELA 5: Médias de incidência (\%) e severidade da Podridão da Base do Estipe (PBE) em mudas de pupunheira inoculadas com isolados de Fusarium spp.

TABLE 5: Average incidence (\%) and severity of stem rot base in peach palm seedlings inoculated with isolates of Fusarium spp.

\begin{tabular}{ccccc}
\hline Isolados & Procedência & Espécie & Incidência & Severidade \\
\hline SP5 & Plântulas & Fusarium proliferatum & $100 \mathrm{a}$ & $4,0 \mathrm{a}$ \\
1A & Semente & Fusarium oxysporum & $80 \mathrm{~b}$ & $2,3 \mathrm{~b}$ \\
3A & Semente & Fusarium sp. & $100 \mathrm{a}$ & $2,5 \mathrm{~b}$ \\
\hline
\end{tabular}

Em que: ${ }^{1}$ Baseada em escala descritiva de notas ( 1 a 4 ) para a doença PBE. Médias seguidas pela mesma letra na coluna, não diferem entre si, pelo teste de Tukey, a $5 \%$ de probabilidade de erro.

metílico + clorotalonil e tiofanato metílico foram significativamente superiores em relação à testemunha no controle da incidência de Fusarium sp. em sementes de pupunheira (Tabela 6). O tratamento com tiofanato metílico + clorotalonil foi o único a obter $100 \%$ de controle de Fusarium sp.

No controle de outros fungos (Aspergillus sp., Trichoderma sp., Trichothecium sp., Rhyzopus sp. e Helminthosporium sp.), todos os tratamentos com fungicidas e hipoclorito de sódio diferiram da testemunha; porém, os tratamentos tiofanato metílico + clorotalonil, tiofanato metílico + captana e tiofanato metílico apresentaram maior eficiência de controle (Tabela 6).

Em alguns tratamentos tais como captana, tiofanato metílico, clorotalonil + tiofanato metílico, foi observada a presença do fungo Schizophyllum commune Fr.. Este fungo é relatado como endofítico e já foi encontrado em sementes de dendezeiro (Elaeis guineensis) por Bezerra e Oliveira (1984) e, em madeira de pupunheira, por Jesus e Abreu (2002).

Há poucos trabalhos sobre o tratamento de sementes de pupunheira. Bovi (1998) relataram a eficiência do fungicida thiram no controle de Fusarium spp.; enquanto que o fungicida thiabendazole não controlou os fungos presentes nas sementes, mas apresentou efeito fitotóxico sobre a germinação e vigor das sementes de pupunheira. Coates-Beckford e Chung (1987) também constataram a presença de Fusarium spp. em sementes de pupunheira. Ainda, segundo CoatesBeckford e Chung (1987), os fungicidas benomil e clorotalonil foram ineficientes no controle destes fungos.

O hipoclorito de sódio tem sido usado no tratamento de sementes de pupunheira. No entanto, conforme observado neste trabalho e relatado por, a desinfestação com hipoclorito de sódio apresenta uma baixa eficiência de controle de fungos.

TABELA 6: Médias de incidência (\%) de Fusarium spp. para os seis tratamentos em que foram submetidas as sementes de pupunheira dos lotes 02E e VR1.

TABLE 6: Average incidence (\%) of Fusarium spp. for the six treatments in which the seeds were subjected to lots of peach palm 02E and VR1.

\begin{tabular}{lcc}
\hline Tratamentos & Incidência de Fusarium spp. (\%) & $\begin{array}{c}\text { Incidência de outros fungos }{ }^{1} \\
(\%)\end{array}$ \\
\hline Captana & $3,5 \mathrm{ab}$ & $15,50 \mathrm{bc}$ \\
Tiofanato metílico + Clorotalonil & $0 \mathrm{~b}$ & $5,00 \mathrm{c}$ \\
Tiofanato metílico & $1,5 \mathrm{~b}$ & $4,50 \mathrm{c}$ \\
Tiofanato metílico + Captana & $4,5 \mathrm{ab}$ & $5,50 \mathrm{c}$ \\
Hipoclorito de sódio & $7,0 \mathrm{ab}$ & $23,50 \mathrm{bc}$ \\
Testemunha & $9,5 \mathrm{a}$ & $38,00 \mathrm{a}$ \\
\hline
\end{tabular}

Em que: Médias seguidas pela mesma letra na coluna, não diferem entre si, pelo teste de Tukey, a $5 \%$ de probabilidade de erro. ${ }^{1}$ Outros fungos: Aspergillus sp., Trichoderma sp., Trichothecium sp., Rhyzopus sp. e Helminthosporium sp. 
A incidência média de Fusarium spp. nas sementes para o lote $02 \mathrm{E}$ foi de $2,78 \%$, enquanto para o lote VR1 foi $5,75 \%$.

\section{Germinação e Vigor}

Com relação à germinação e vigor, não houve diferença significativa entre os lotes e entre os tratamentos pelo teste $\mathrm{F}$ (Anova). Os dados médios de índice de velocidade de germinação, velocidade de germinação e germinação encontramse na Tabela 7.

\section{CONCLUSÕES}

- $\quad$ O método do papel-cartão mostrou-se eficaz na recuperação de Fusarium spp. de sementes de pupunheira;

- Fusarium spp. pode ser transmitido de sementes para plântulas;

- Fusarium oxysporum e Fusarium proliferatum foram isolados de sementes e plântulas, respectivamente, e considerados patogênicos à pupunheira;

- Osfungicidastiofanatometílico+clorotalonil e tiofanato metílico foram eficientes no controle de Fusarium spp. em sementes de pupunheira;

- $\quad$ Os lotes Reca, T e VR1 mostraram-se os mais vigorosos, tanto para germinação quanto para emergência.

\section{REFERÊNCIAS BIBLIOGRÁFICAS}

ANDERSON, R. L. A new method for assessing contamination of slash and loblolly pine seeds by Fusarium moniliforme var. subglutinans. Plant Disease, Saint Paul, v. 70, n. 5, p. 452-453, 1986.

BARNETT, H. L.; HUNTER, B. B. Illustrated genera of imperfect fungi. Minnesota: Burgess Publishing Company, 1972. $241 \mathrm{p}$.

BOVI, M. L. A. Palmito - pupunha (Bactris gasipaes Kunth). In: FAHL, J. I. et al. (Eds.). Instruções agrícolas para as principais culturas econômicas. 6. ed. Campinas: Instituto Agronômico, 1998. p. 269-271.

BOVI, M. L. A. O Agronegócio Palmito de Pupunha. O Agronômico, Campinas, v. 52, n. 1, p. 10-12. 2000.

BOVI, M. L. A. et al. Seed germination of progenies of Bactris gasipaes: percentage, speed and duration. Acta Horticulture, Wageningen, v. 360, p. 157-165, 1993.

BRASIL. Ministério da Agricultura, Pecuária e Abastecimento. Regras para análise de sementes. Brasília, DF: Mapa/ACS, 2009. 395 p.

CARDOSO, W. Sementeiras em serragem. Boletim de Secção de Fomento Agrícola no estado do Pará, Belém, v. 3, n. 2, p. 27-33, 1944.

CARVAlHO, J. E. U.; MÜlLER, C. H. Níveis de tolerância e letal de umidade em sementes de pupunheira, Bactris gasipaes. Revista Brasileira de Fruticultura, Cruz das Almas, v. 20, p. 283-289, 1998.

COATES - BECKFORD, P. L.; CHUNG, P. C. A study of the germination, disease symptoms, and fungi associated with pejibaye seeds. Seed Science and Technology, Wageningen, v. 15, n. 1, p. 205-218, 1987.

TABELA 7: Índice de Velocidade de Germinação (IVG) e Velocidade de Germinação (VG) e Germinação para os seis tratamentos nos dois lotes de sementes de pupunheira.

TABLE 7: Germination Velocity Rate (GVR) and Germination Velocity (GV) and Germination or the six treatments in two batches of peach palm seeds.

\begin{tabular}{lccc}
\hline \multicolumn{1}{c}{ Tratamento } & IVG & VG & Germinação (\%) \\
\hline Captana & 0,24 & 47,84 & 51,5 \\
Tiofanato Metílico & 0,21 & 42,56 & 41,5 \\
Captana + Tiofanato metílico & 0,17 & 41,82 & 43 \\
Clorotalonil + Tiofanato metílico & 0,16 & 41,78 & 39 \\
Hipoclorito & 0,15 & 41,69 & 38,5 \\
Testemunha & 0,14 & 40,21 & 37,5 \\
\hline
\end{tabular}


CLEMENT, C. R.; MORA-URPÍ, J. Pejibaye palm (Bactris gasipaes, Arecaceae): multi-use potential for the lowland humid tropics. Economic Botany, New York, v. 41, n. 2, p. 302-311, 1987.

COSTA JUNIOR, J. C. Qualidade sanitária e fisiológica de sementes de pupunheira submetidas a tratamento químico e caracterização dos sintomas da podridão da base do estipe causada por Fusarium spp. 2013. 127 f. Dissertação (Mestrado em Agronomia) - Universidade Federal do Paraná, Curitiba, 2013.

CROCOMO, W. B.; GUASSU, C. M. O.; NAKAGAWA, J. Avaliação da qualidade fisiológica de sementes de algodão, amendoim e feijão tratadas com inseticidas sistêmicos. Cientifica, Sao Paulo, v. 17, n. 1, p. 157-167, 1989.

DOYLE, J. J.; DOYLE, J. L. Isolation of plant DNA from fresh tissue. Focus, Chile, v. 1, p. 13-15, 1991.

EDMOND, J. B.; DRAPALLA, W. J. The effects of temperature, sand and soil, and acetone on germination of okra seed. Proceedings of the American Society for Horticultural Science, New York, v. 71, p. 428-443, 1958.

FERREIRA, S. A. N. Armazenamento e desenvolvimento do teste de tetrazólio em sementes de pupunha (Bactris gasipaes H.B.K.). 1988. 64 f. Dissertação (Mestrado) - UNESP/FCAV, Jaboticabal, 1988.

FERREIRA, S. A. N. Pupunheira, Bactris gasipaes Kunth. In: FERRAZ, I. D. K.; CAMARGO, J. L. C. (Eds). Manual de Sementes da Amazônia. Manaus: INPA, 2005. 12 p. (Fascículo 5).

FERREIRA, S. A. N.; SANTOS, L. A. Viabilidade de sementes de pupunheira (Bactris gasipaes Kunth.). Acta Amazônica, Manaus, v. 22, n. 3, p. 303-307, 1992.

FORCELINI, C. A. Importância epidemiológica de fungos do gênero Helminthosporium em sementes de trigo e cevada. In: MENTEN, J. O. M. (Ed.). Patógenos em sementes: detecção, danos e controle químico. Piracicaba: ESALQ/FEALQ, 1991. p. 179-190.

GEISER, D. et al. A DNA sequence database for identifying Fusarium. European Journal of Plant Pathology, Berlin, v. 110, p. 473-479, 2004.

MEEROW, A. W. Palm seed germination. IFAS
Cooperative Extension Bulletin, Flórida. v. 274, p. 1-10, 1991.

MORO, J. R. Produção de palmito de pupunheira no nordeste do Brasil: variabilidade genética e desenvolvimento de cultivares. In: QUEIROZ, M. A.; GOEDERT, C. O.; RAMOS, S. R.R. (Ed.). Recursos genéticos e melhoramento de plantas para o nordeste brasileiro. Brasília, DF: Embrapa Recursos Genéticos e Biotecnologia, 1999.

NAKAGAWA, J. et al. Estudo de testes para avaliar a qualidade fisiol6gica das sementes de amendoim.

Revista Brasileira de Sementes, Brasília, v. 5, n. 3, p. 63-76, 1983.

NEERGAARD, P. Detection of seed-borne pathogens by culture tests. Seed Science and Technology, Bassersdorf, v. 1, p. 217-254, 1973.

NEERGAARD, P. Seed pathology. London: Mac Millan Press, 1979. v. 1, 829 p.

PIZZINATO, M. A. et al. Patogenicidade de cinco espécies de Fusarium a planta de pupunheira (Bactris gasipaes). Summa Phytopathologica, Botucatu, v. 27, n. 2, p. 263-268, 2001.

REIS, E. M. et al. Comparison of methods to detect leaf and head blighting fungi in small grain seeds.

Summa Phytopathologica, Botucatu, v. 25, p. 364 367, 1999.

SANTOS, A. F.; CORRÊA, C.; NEVES, E. J. M. (Eds.). Palmeiras para produção de palmito: juçara, pupunheira e palmeira real. Colombo: Embrapa Florestas, 2008. 190 p.

SANTOS, A. F.; PARISI, J. J .D.; MENTEN, J.O.M. (Eds). Patologia de Sementes Florestais. Colombo: Embrapa Florestas, 2011. 236 p.

SANTOS, A. F. et al. As doenças da pupunheira (Bactris gasipaes Kunth): antracnose e podridão da medula. Colombo: Embrapa Florestas, 2001. 3 p. (Embrapa Florestas. Comunicado Técnico, 63).

SANTOS, A. F. et al. Manejo fitossanitário em viveiros de palmeiras para palmito. Colombo: Embrapa Florestas, 2007. 9 p. (Embrapa Florestas. Circular técnica, 146).

TSUBOI, H. Estudos da formação de mudas de maracujazeiro amarelo (Passiflora edulis Sims f. flavicarpa Deg.). 1990. 117 f. Dissertação (Mestrado) - UNESP/Faculdade de Ciências Agronômicas, Botucatu, 1990. 